\title{
Molecular and biochemical aspects of interphase nucleolar organiser regions
}

\author{
J Crocker
}

Much has been written in the last eight or so years concerning the clinical applications of the measurement or enumeration of interphase nucleolar organiser regions (NORs) in tissue sections. ${ }^{12}$ This is because these structures are readily demonstrated in archival or current histological material and because it has been shown repeatedly that the numbers of NORs or amount of NOR material in a nucleus closely reflects its proliferative status.

NORs are structures present in the short arms of the acrocentric chromosomes in humans and were first detected on Giemsa banding as "achromatic gaps" with much reduced staining. The areas are not, of course, genuine gaps but are areas of specialised chromosomal configuration. Cytogeneticists have made use of the evaluation of NORs for many years in metaphase spreads as a means of showing abnormalities affecting the acrocentric chromosomes. Examples of the value of NOR study in chromosomal preparations include the demonstration of balanced and unbalanced translocations and of polymorphic variants on the short arms of the latter chromosomes (numbers 13, 14, 15, 21, and 22) and the highlighting of micronucleoli (in meiotic specimens).

The major advance in the demonstration of NORs came with the discovery that they are highly argyrophilic, because of the properties of some of their associated proteins. ${ }^{3}$ Accordingly, one of the most popular methods for demonstrating these areas has made use of the binding of $\mathrm{Ag}^{+}$ions and the structures revealed have been assigned the rather unattractive name "AgNORs". ${ }^{2}$ It was shown, then, that the achromatic gap areas on the acrocentric chromosomes were argyrophil and the silver binding method became a standard. Given the increasing understanding of the properties of chromosomal NORs, it was clearly necessary to follow this with more detail on the functional role of these entities and the proteins with which they are associated. Probably the most important discovery was that of the underlying nucleolar structures which represent the interphase analogues of the chromosomal NORs. Thus it is known that when a cell completes the proliferative phases of the cycle, the NORs fuse to form parts of the nucleolus, which are in turn central to the synthesis of ribosomes. ${ }^{4}$ The upsurge of interest by pathologists in interphase NORs, that is to say the structures within nucleoli which correspond to the metaphase NORs, lies in their expectation that these components might reflect the proliferative status of the cell. This is a tenet that is held because it would be logical to assume that the NOR "ribosome factories" should in turn relate to the state of "activation" of the nucleus.
It was found repeatedly that the numbers of histochemically stained NORs in interphase cells represented their proliferative state rather than any other variable, such as, for example, protein synthetic level. ${ }^{5-9}$ Accordingly, diagnostic pathologists worldwide have applied the simple methods available for the demonstration of NORs to a wide range of neoplasms of both solid and diffuse type. In general it has been found that the mean "score" of NORs per nucleus represents the proliferative state or reflects the prognosis in these tumours. ${ }^{2}$ In view of the extensive clinicopathological literature in this field, it seems, therefore, to be timely to outline the molecular and biochemical bases of the function of the NOR and the techniques used to demonstrate it.

\section{The nucleolar organiser region}

The nucleolar organiser region is the part of the genome representing the ribosomal RNA complex (that is, the rRNA cistron). ${ }^{10}$ It is therefore central to protein assembly and synthesis and would be expected to be of intricate molecular structure. In the average dividing cell, approximately 400 rRNA genes can be working, even though they may represent only a fairly small component of the available nucleolar DNA. When the rRNA genes are transcribed, they do so as a unit, with the $18,5 \cdot 8$, and $28 \mathrm{~S}$ areas all involved, although they are separated by a non-transcribing zone, or spacer. ${ }^{11}$ (fig 1). This latter is very rich in 5-methyl cytosine (5-MeCyt) bases, as has been shown by means of immunocytochemistry, and is an area of great potential for gene amplification. These spacer areas vary in length but have considerable homology, suggesting repetition of internal sequences.

When RNA is transcribed, it does so in a tandem "Christmas tree" fashion (fig 2), the nascent molecules being "read" off and are surrounded by protein granules (at the 5 ' end) which in turn are probably involved in the synthetic process. Within one hour the $28 \mathrm{~S}$ subunits appear in the cytoplasm, being preceded by the $18 \mathrm{~S}$ units some 30 minutes earlier. This process is catalysed by RNA polymerase I (see below) which enables a transcription rate

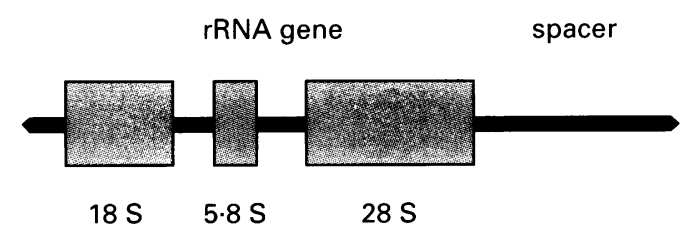

Figure $1 A$ simple representation of the $r R N A$ gene with its adjacent non-transcribing "spacer" area. 


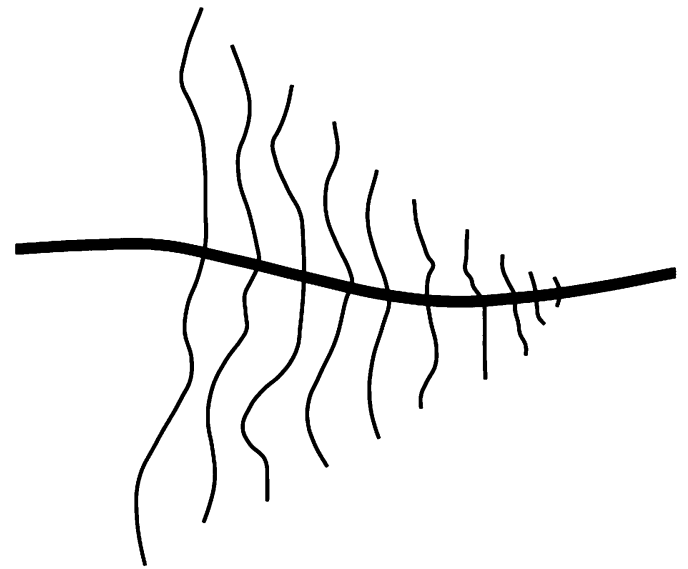

Figure 2 The "Christmas tree" effect observed in spreads from transcribing nucleolar organiser regions (NORs). Nascent molecules are formed, in increasing length, in tandem, from the NOR locus.

of about 40 nucleotides per second. The total of nucleotide bases processed, cumulatively, for the $45,28,18$, and $5 \cdot 8 \mathrm{~S}$ subunits amounts to approximately 20160 of which some 6800 units are lost in the conversion. The complexity of the entire transcription can be further stressed when it is realised that each of the acrocentric chromosomes bears about 200 rRNA gene copies! There are non-variable sequences of $28 \mathrm{~S}$ rRNA but it could be that the large rate of change of rRNA sequences across the evolutionary landscape is explained by the situation of the variable areas at the periphery of the ribosomes, perhaps allowing easy access by external modifiers, such as viruses or other factors. ${ }^{12}$

\section{NOR associated proteins (NORAP)}

There are at least 200 proteins involved in the structural and functional organisation of the nucleolus. These include protein products directly encoded by the NOR itself and histone and non-histone proteins. Some of the most important entities on this list are described below. Their sites in the three zones of the nucleolus are depicted in fig 3.

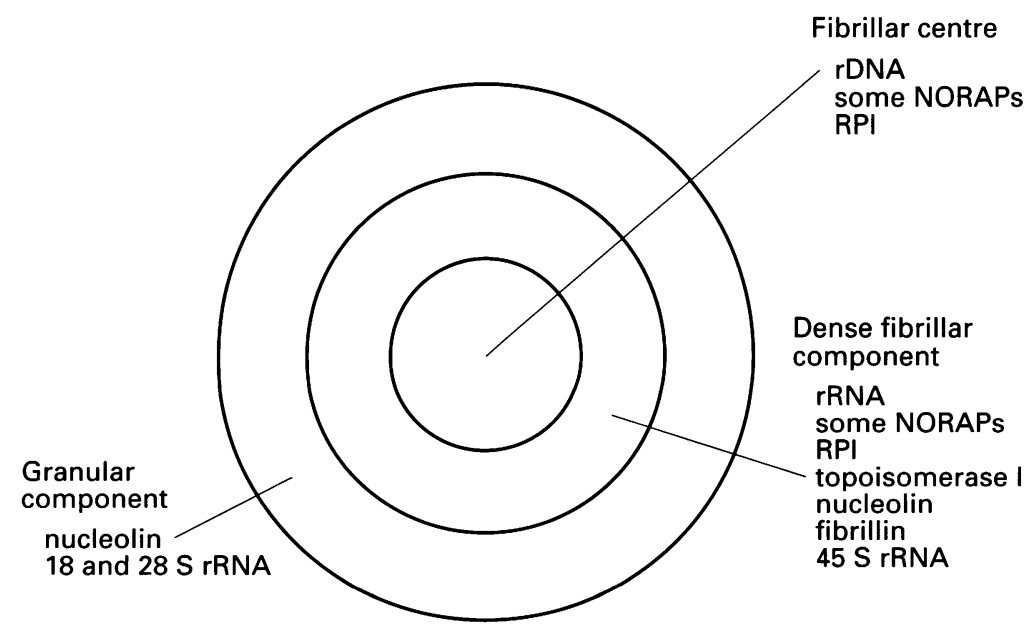

Figure 3 The three layers of the interphase nucleolus, with a listing of some of their relevant molecules.
RNA POLYMERASE I (RPI)

This enzyme is obligatory for rDNA transcription. It appears as a functional unit but in reality exists as a series of proteins which react with anti-RPI. These proteins include RPI cofactors and a probable NOR-related protein. The enzyme RPI itself is composed of eight subunits, ranging from $17 \cdot 5-190 \mathrm{kDa}$ in size. The enzyme is present in large amounts in cells, probably amounting to 20-30000 molecules per cell.

\section{C23 PROTEIN ("NUCLEOLIN")}

When cells are growing exponentially, C23 is the major protein expressed. The protein is quintessential to the transcription of rRNA genes and binds to histone $\mathrm{H} 1$, leading to the "opening up" of these areas, allowing access to RPI. Nucleolin is also important in the handling of new RNA transcripts and may be involved in the kinase sequence of the cell cycle. Its phosphorylation endows it with strong argyrophil properties and it is a well defined AgNOR protein ${ }^{13}$ (see below). Transfection experiments, using cells of differing species have shown that RP II, rather than RP I can then transcribe rRNA; however, when this occurs argyrophilia is lost from the acrocentric chromosomes of the donor. It has been suggested that, since nucleolin is the main silver binding NOR associated protein, it may at least in part control RP I. ${ }^{14}$

\section{TOPOISOMERASE I}

This protein has in the past been regarded as a marker of cell proliferation status. It acts to diminish stress in the rDNA helix as it is "read" by RNA polymerase I. Interestingly, the enzyme is absent from the methyl-cytosine-rich nontranscribing segments of the rDNA localities.

\section{B23 PROTEIN ("NUMATRIN")}

This is one of the proteins first recognised as being associated with NORs. It is hexameric, with a size of $38 \mathrm{kDa}$, and like nucleolin is a phosphoprotein. Thus it is probably one of the argyrophil proteins in NORs. It can be shown to increase in mitogenic responses.

\section{FIBRILLARIN}

When $5.8 \mathrm{~S}$ rRNA is cleaved, the process is mediated by small nucleolar (U3) RNA; fibrillarin has been shown to be associated with U3 rRNA and may thus play a role in the cleavage. Fibrillarin has been characterised as a $34 \mathrm{kDa}$ basic protein.

The demonstration of NORs by means of in situ hybridisation

The earliest recognition of the achromatic gaps of the acrocentric chromosomes came with hybridisation of radiolabelled rRNA to metaphase spreads. This was shown in Drosophila melanogaster $^{1516}$ some 20 years ago. Subsequently it was also demonstrated in mam- 
mals. ${ }^{17}$ In the latter study, the hybridisation was performed sequentially with silver binding (see below) and colocalisation of probe and argyrophilia was observed. The sites of rRNA binding and argyrophilia also corresponded to the achromatic gaps seen on Giemsa banding. Non-autoradiographic hybridisation was later applied, using rRNA coupled to mercury ions, which were then allowed to react with a sulphydryl-trinitrophenyl complex (mercury binding) and then with labelled antibody to trinitrophenol. ${ }^{18}$ In the latter study, it was observed that in resting lymphocytes, hybridisation sites were more frequent than were silver stained foci. When the cells were stimulated, however, the converse effect was seen. This is explained by the fact that on stimulation the NORs begin to transcribe, and only transcriptionally active NORs bind silver.

\section{The argyrophilia of NORs}

The silver binding properties of NORs were first described some 20 years ago ${ }^{19}$ and the argyrophil method, in several adaptations, has found widespread use by cytogeneticists and pathologists since that time. The structures stained by virtue of their argyrophilia have more recently been given the name of "AgNORs". These in general correspond to NORs, whether on chromosomes or in interphase, and represent one or more argyrophil-NOR associated proteins ("NORAPs"). The argyrophilia of NORs was first documented in $1975,{ }^{19} 20$ as a result of a three stage technique. Chromosomes were treated sequentially with $\mathrm{AgNO}_{3}$ solution, then ammoniacal silver solution, followed by a formaldehyde developer. In the investigation by Goodpasture and Bloom, ${ }^{19}$ the method was applied to a range of animals corresponding to those previously studied by means of in situ hybridisation with rRNA. ${ }^{1721}$ It was found that the sites of hybridisation corresponded with those of silver binding and it was considered that the latter was a valid and relatively simple method of demonstrating NORs, albeit indirectly. Five year later the argyrophil method was adapted to a one stage technique run at $60^{\circ} \mathrm{C}^{3}$ with reportedly more reproducible results. However, the greatest advance in the methodology of AgNOR staining came from the group in Rheims, who described a one stage method run at room temperature. ${ }^{22}$ This has given rise to many publications regarding the cell biology of NORs and their diagnostic and prognostic values, ${ }^{12}$ because the technique has very little background contamination and gives a suitably small silver particle size. ${ }^{22}$

The mechanism of the argyrophilia is quite well understood and probably occurs in two stages, namely an initial attachment of silver to a reaction site on a protein such as nucleolin, followed by "nucleation" of further silver on the original bound metal, giving a black appearance. If fluorescent tagged probes such as dansyl chloride and fluorescamine, also linked to $\mathrm{Hg}^{+}$, are used to localise NOR sites with, in addition, silver colloid, some most useful information can be gleaned about the chemistry of these sites. This has been coupled with extraction of DNA by DNase and RNA by $\mathrm{RNase}$, as well as proteolysis by pronase, papain, or trypsin, applied to human metaphase spreads. Furthermore, -S-S- and -S-H bonds can be disrupted by the action of cupric sulphite. It has been shown that proteolysis and removal of sulphur containing groups abolishes mercury probe or silver binding. However, removal of nucleic acids or histones has no effect on the binding reactions. ${ }^{23}$ It appears, then, that the NOR sites on the acrocentric chromosomes bind silver or mercury by virtue of $-S-S$ - and $-\mathrm{S}-\mathrm{H}$ groups in associated proteins. It has also been proposed that these very groups may be important in creating molecular flexibility, enabling access to NOR sites. ${ }^{23}$

Further investigation of the chemistry of the "AgNOR" reaction was performed by means of PAGE on cellular nucleolar preparations. ${ }^{24}$ Nucleolar phosphoproteins with sizes of 104, 78,37 and $29 \mathrm{kDa}$ were reactive with both silver and the Giemsa stain usually employed in chromosome banding studies. The Giemsa reaction appeared to depend on the presence of phosphorylated protein sites, whereas argyrophilia also required the availability of carboxyl groups. This seems to conflict with the previous investigations where sulphur containing moieties seemed to be most important for silver binding. However, this may not be the case, since it is not necessarily possible to relate the findings in nuclei or chromosomes to those in PAGE strips. Indeed, it has been proposed that the binding of silver may be sequential. Thus it could be that silver first binds to carboxyl groups, then nucleates round disulphide and sulphydryl groups. ${ }^{25}$ Certainly, pretreatment of tissues with mercury ions abolishes the AgNOR reaction, presumably by competing with silver ions for attachment to the -S-S- and -S-H groups. Likewise, treatment or fixation of tissues with dichromates also inhibits the AgNOR reaction, because of oxidation of these groups to cysteic acid.

By means of immunoelectronmicroscopy and ultrastructural histochemistry, there has been substantial progress in our understanding of the functional organisation of the nucleolus. The organelle consists of three layers, namely: the outer granular zone, beneath which lies the dense fibrillar zone, and then the innermost fibrillar centre ${ }^{1}$ (fig 3). These have differing functions and represent the sequence of ribosomal synthesis, running centrifugally and with preribosomes being represented by the outer granular zone. The names of the components are derived from their appearances on conventional electron microscopy. The AgNOR reaction can be performed at the ultrastructural level and it was initially shown that silver was bound at the NOR sites on chromosomes and in the fibrillar centres in interphase cells. ${ }^{26}$ When simultaneous AgNOR and Giemsa staining are performed for electron microscopy, intranucleolar fibres are seen to overlap with the grains of the AgNOR product. ${ }^{27}$ The fact that AgNOR associated chromatin is in this dispersed form is related to its involvement in active transcription. Later studies of the binding of silver to the nucleus 
have shown that part of the dense fibrillar zone reacts, as well as the fibrillar centre. ${ }^{28}$ Selective ultrastructural histochemistry has further confirmed the protein non-nucleic-acid nature of the moities responsible for the argyrophil reaction. ${ }^{29}$

\section{Summary}

This review has outlined the molecular basis of the complex structure, the nucleolar organiser region. The topographical construction of the interphase nucleolus relates well to its function as a "ribosome factory" and the chemical basis of the function of this unit and its transcription is increasingly well understood. The central importance of the chromosomal and interphase NORs to protein synthesis, and especially to the cell cycle, accounts for much of the recent interest in the structures by cell biologists and pathologists alike.

I am most grateful to Stephen Crocker for advice and support with computer graphics.

1 Crocker J. Nucleolar regions, fibrillar centres and lymphomas. In: Crocker J, ed. Cell proliferation in lymphomas. Oxford: Blackwell Scientific Publications, 1993:145-84.

2 Derenzini $M$, Ploton $D$. Interphase nucleolar organizer regions. In: Crocker J, ed. Molecular biology in histopathology. Chichester: John Wiley, 1994:121-49.

3 Howell WM, Black DA. Controlled silver staining of nucleolus organizer regions with a protective colloidal developer: a one-step method. Experientia 1980;31:1014.

4 Hernandez-Verdun D. The nucleolar organiser regions. Biol Cell 1983;49:191-202.

5 Crocker J, Macartney JC, Smith PJ. Correlation between DNA flow cytometric and nucleolar organizer region data in non-Hodgkin's lymphomas. $\mathcal{F}$ Pathol 1988;154:151-6.

6 Hall PA, Crocker J, Watts A, Stansfeld AG. A comparison of nucleolar organiser region staining and $\mathrm{Ki} 67 \mathrm{im}$ munostaining in non-Hodgkin's lymphoma. Histopathology 1988;12:373-81.

7 Derenzini M, Pession A, Treré D. The quantity of nucleolar silver-stained proteins is related to proliferating activity in cancer cells. Lab Invest 1990;63:7-40.

8 Janmohamed RM, Armstrong SJ, Crocker J, Leyland MJ, Hulten MA. The relationship between number of interphase NORs and NOR-bearing chromosomes in nonterphase NORs and NOR-bearing chromosom

9 Crocker J, Nucleolar organizer regions and fibrillar centres. In: Herrington CS, McGee J'OD, eds. Diagnostic molecular pathology. A practical approach. Oxford: IRI Press, 1992:222-38.

10 Henderson AA, Warburton D, Atwood KC. Location of ribosomal DNA in the human chromosome complement. Proc Natl Acad Sci USA 1972;69:3394-8.
11 Miller OJ, Tantravahi U, Katz R, Erlanger BF, Guntaka RV. Amplification of mammalian rRNA genes and their regulation by methylation. In: Arrighi FE, Rao PN, Stubblefield $\mathrm{E}$, eds. Genes, chromosomes and neoplasia. New York: Raven Press, 1981:253-70.

12 Schmickel RD. The molecular organisation of the human ribosomal gene. In: Stahl A, Luciana JM, Vagner-Capodano AM, eds. Chromosomes today, vol 9. London: Allen and Unwin, 1987.

13 Roussel P, Belenguer P. Amalric F, Hernandez-Verdaun D. Nucleolin is an AgNOR protein; this property is determined by its amino-terminal domain independently of termined by its amino-terminal domain independently of

14 Jordan G. At the heart of the nucleolus. Nature $1987 ; 329$. 489-90.

15 Ritossa FM, Speigelman S. Localization of DNA complementary to ribosomal RNA in the nucleolus organised region of Drosophila melanogaster. Proc Natl Acad Sci USA 1965;53:737-45.

16 Wallace H, Birnsteil ML. Ribosomal cistrons and the nucleolar organizer. Biochim Biophys Acta 1966;114:296-310.

17 Hsu TC, Spirito SE, Pardue ML. Distribution of $18+28$ $S$ ribosomal genes in mammalian genomes. Chromosoma 1975;53:25-36.

18 Wachtler F, Hopman AHN, Wiegant J, Schwarzacher HG. On the position of nucleolus organizer regions (NORs) in interphase nuclei. Studies with a new, non-autoradiographic in situ hybridization method. Exp Cell Res 1986;167:227-40.

19 Goodpasture C, Bloom SE. Visualization of nucleolar organizer regions in mammalian chromosomes using silver staining. Chromosoma 1975;53:37-50.

20 Howell WM, Denton TE, Diamond JR. Differential staining of the satellite regions of human acrocentric chromosomes. Experientia 1975;31:260-2.

21 Pardue ML, Hsu TC. Locations of $18 \mathrm{~S}$ and $28 \mathrm{~S}$ ribosomal genes on the chromosomes of the Indian muntjac. $f$ Cell Biol 1975;64:251-4.

22 Ploton D, Menager M, Jeannesson P, Himber G, Pigeon F, Adnet J-J. Improvement in the staining and in visualization of the argyrophilic proteins of the organizer region at the optic level. Histochem $\mathcal{F}$ 1986;18:5-14.

23 Buys CHCM, Osinga J. A relation between G-, C- and Nband patterns as revealed by progressive oxidation of chromosomes and a note on the nature of N-bands. Genetics 1982;58:3-9.

24 Buys CHCM, Osinga J. Selective staining of the same set of nucleolar phosphoproteins by silver and Giemsa. A combined biochemical and cytochemical study on staining of NORs. Chromosoma 1984;89:387-96.

25 Smith PJ, Skilbeck NQ, Harrison A, Crocker J. The effect of a series of fixatives on the AgNOR technique. $\mathcal{F}$ Pathol 1988:155:109-12.

26 Hernandez-Verdun D, Hubert J, Bourgeois CA, Bouteille M. Ultrastructural localisation of Ag-NOR stained proteins in the nucleolus during the cell cycle and in other nucleolar structures. Chromosoma 1980;79:349-62.

27 Hernandez-Verdun D, Derenzini M, Bouteille $M$. The morphological relationship in electron microscopy between
NOR-silver proteins and intranucleolar chromatin. Chromosoma 1982;85:461-73.

28 Ploton D, Menager M, Adnet J-J. Simultaneous high-resolution localization of Ag-NOR proteins and nucleoplution localization of Ag-NOR proteins and nucleo-
proteins in interphase and mitotic nuclei. Histochem $\mathcal{f}$
$1984 ; 16: 897-906$.

29 Moreno FJ, Hernandez-Verdun D, Masson C, Bouteille M. Silver staining of the nucleolar organizer regions (NORs) on Lowicryl and cryo-ultrathin sections. $\mathcal{f}$ Histochem $\mathrm{Cy}$ tochem 1985;33:389-99. 